\title{
Resistencia civil contra megaproyectos. Análisis del movimiento ¡Hambi bleibt! en Alemania
}

Civil resistance against megaproyects. Analysis of the movement ¡Hambi bleibt! in Germany

Feline GerstenberG

Universidad de Granada gerstenberg.f@gmail.com

\section{Resumen}

Alemania es conocida internacionalmente por el movimiento ecologista de los años 70 y el liderazgo que ejerce en el desarrollo de acciones y medidas para la protección de la naturaleza. A pesar de dichos esfuerzos, hoy en día, sigue siendo el productor más importante de lignito del mundo, también conocido como carbón marrón. En un lugar cerca de la ciudad de Colonia, se encuentra la mina de lignito a cielo abierto más grande de Europa llamada Hambach. Para que la empresa energética RWE, dueña de la mina, pueda ampliar su territorio, quiere deforestar completamente el Bosque de Hambach. Se trata de un bosque de 12000 años que queda al lado de la mina. Desde 2012, distintas personas están resistiendo contra la deforestación y RWE. Durante el transcurso del tiempo, se construyó un movimiento bajo el lema ;Hambi bleibt!1. Este artículo quiere dar respuesta a la pregunta, hasta qué punto se trata de una resistencia no-violenta. Para esto, se realizaron entrevistas cualitativas con nueve personas que forman parte de los procesos de resistencia y también se analizaron artículos y materiales audiovisuales. El resultado clave es que la mayoría de las personas actúa con métodos de acción no-violenta y que la autoimagen se distingue claramente de la atribución externa. El artículo amplía la Investigación para la Paz con respecto a conflictos socio-ambientales actuales.

Palabras clave: resistencia civil, noviolencia, minería, Alemania, conflicto socioambiental, extractivismo, movimiento ecologista

\begin{abstract}
Germany is internationally known for the environmental movement of the 70 s and the leadership it exercises in the development of actions and measures for the protection of nature. Despite these efforts, today, it is still the most important lignite producer in the world, also known as brown coal. In a place near the city of Cologne, there is the largest open pit brown coal mine in Europe called Hambach. In order to expand its territory, the energy company RWE, owner of the mine, wants to deforest the Hambach Forest completely, a 12,000-year-old forest that is located next to the mine.

Since 2012, different people are resisting against the deforestation and RWE. During the course of time, a movement was built under the motto Hambi bleibt!2. This article wants to answer the question, to what extent it is a non-violent resistance. Therefore, qualitative interviews were
\end{abstract}

\footnotetext{
${ }^{1}$ En español: ¡Hambi se queda!

2 In English: Hambi stays!
} 
conducted with nine people who are part of the resistance processes and audiovisual articles and materials were also analyzed. The key result is that most people act with non-violent methods and that the self-image is clearly that the self-image differs clearly from external attribution from external attribution. The article expands the Research for Peace regarding current socioenvironmental conflicts.

Keywords: civil resistance, nonviolence, mining, Germany, socio-environmental conflict, extractivism, ecological movement 


\section{Introducción 3}

En verano de 2018 la sueca Greta Thunberg de 16 años decidió protestar contra el cambio climático con huelgas escolares. De ahí se derivó el movimiento ambientalista Fridays for Future (FfF) que cada vez se pone más popular. Hasta ahora, las huelgas experimentaron su pico el 15 de marzo de 2019, cuando más de 2 millones de personas, en 135 países, participaron en la protesta $(\mathrm{FfF}$, 2019). Las protestas de Greta y de otros activistas ecologistas muestran el poder que tiene la lucha noviolenta para actuar contra el cambio climático y visibilizar problemáticas globales.

Este artículo se enfoca en un movimiento de resistencia civil contra la deforestación del Bosque de Hambach que ha llamado mucho la atención no sólo en Alemania, sino internacionalmente. Mientras que los políticos alemanes se muestran como entusiastas defensores del medio ambiente, evitan hablar sobre el hecho de que alrededor del 35\% de la demanda de electricidad del país se cubre con el carbón ${ }^{4}$ y que este es el mayor productor de lignito del mundo (Bauchmüller, 2018). Según la Liga Alemana para la Protección del Medio Ambiente y de la Naturaleza (abreviatura en alemán: BUND) 5 , el lignito que también es conocido como carbón marrón, es la fuente energética más dañina que existe para el medio ambiente.

Es importante analizar el caso del Bosque de Hambach por el gran número de participantes, la diversidad de personas e iniciativas locales y nacionales que protestan y el impacto que han conseguido en los medios de comunicación. Como reflejan varios artículos, la resistencia ha cambiado negativamente la imagen de la empresa energética RWE y ha encendido la presión hacia los políticos para salir del carbón lo más pronto posible. Es probable que la protesta en el Bosque de Hambach también haya tenido un impacto positivo en los resultados de las elecciones europeas de 2019 para el partido Los Verdes 6 alemán, el cual había perdido mucha confianza en la población durante los últimos años. Por esto sorprendió cuando logró más del $20 \%$ de los votos en su país, casi el $10 \%$ más que en 2014. Aparte de esto, el artículo conecta la Investigación para la Paz con conflictos socio-ambientales.

El texto se estructura de la siguiente manera: en primer lugar se realiza una aproximación a los conceptos de la resistencia civil y la noviolencia. También se crea una vinculación con el cambio climático. A continuación, se da paso a la descripción del caso que analizamos, ofreciendo primero una breve revisión histórica del movimiento ecologista de Alemania, datos generales sobre

\footnotetext{
3 Artículo derivado como proyecto de investigación para la tesis fin de master del programa de posgrado "Cultura de Paz, Derechos Humanos, Conflictos y Educación" ofrecido por el Instituto de Paz y Conflictos (IPAZ) de la Universidad Granada (España). La tesis lleva el título “¡Hambi bleibt! Análisis del movimiento de resistencia civil contra la deforestación del Bosque de Hambach en Alemania". Fecha de entrega: 31.07.2019. Fecha de aprobación: 30.09.2019.

4 En 2017, el 39\% de la demanda de electricidad se cubría con el carbón (casi 15\% carbón de piedra y $24 \%$ carbón marrón). En total, las energías no-renovables cubrían el $61,8 \%$ de la demanda y solo el 38,2\% eran de energías renovables (Fraunhofer, 2018).

5 En alemán: Bund für Umwelt und Naturschutz Deutschland (BUND).

${ }^{6}$ En alemán: Die Grünen.
} 
el Bosque de Hambach y la minería en Alemania, la legislación y los actores en esta resistencia. Por último, se presentan los resultados de la investigación y una discusión sobre la pregunta de investigación: ¿Hasta qué punto fue no-violenta la resistencia?

\section{Metodología}

La metodología utilizada es de corte cualitativo ya que el objetivo es conocer con detalle las perspectivas y experiencias de diferentes personas. El análisis se divide en dos partes: primero, por el hecho de que se trata de un tema poco investigado académicamente, se realizaron entrevistas semiestandarizadas con personas que han actuado en contra de la deforestación. Para llevar a cabo este tipo de entrevistas cualitativas, se hizo uso de una guía de preguntas. La investigadora trabajó con un espectro amplio de preguntas abiertas 0 estructuradas por una teoría.

Para sus estudios de pregrado, ella había analizado las consecuencias de la extracción minera para mujeres rurales en Colombia. La estadía de investigación en la Universidad
Católica de Colombia incluyó un viaje a la comunidad El Hatillo donde la autora entrevistó a mujeres afectadas. Dichas experiencias que ella adquirió facilitaron la organización y realización de las entrevistas para el presente trabajo. Por ejemplo, ella ofrece un alto nivel de sensibilidad y empatía, algo que le ayuda para comunicarse con personas difícilmente accesibles con respecto al lugar donde viven o a la personalidad que tengan.

El objetivo de las entrevistas era cubrir el amplio espectro de resistencias. Para la selección de las personas se hizo una revisión extensa de la literatura y de materiales audiovisuales. Durante este proceso, ciertas personas e iniciativas fueron destacadas como líderes ${ }^{7}$ del movimiento ;Hambi bleibt!. Esto obedecía a su frecuente presencia en los medios de comunicación, el número de participantes (cuando se trata de una iniciativa) y su poder de movilización (representación en medios sociales, etc.). Para poder analizar mejor, tanto sus estrategias, como el impacto que han tenido, fueron divididos en tres grupos $^{8}$ que se muestran en la Tabla 1.

\footnotetext{
${ }^{7}$ Aquí, el término líder no significa que alguna iniciativa o persona se sitúa jerárquicamente encima de los demás. Las personas e iniciativas son independientes entre sí.

8 Más adelante en el trabajo habrá una caracterización más detallada de los actores.
} 
TABLA 1. LOS ACTORES DE LA RESISTENCIA (ELABORACIÓN PROPIA)

\begin{tabular}{|c|c|c|}
\hline & Personas claves/Iniciativas & Descripción \\
\hline $\begin{array}{l}\text { Las y los ocupantes } \\
\text { del Bosque }\end{array}$ & Clumsy y Indigo (sinónimos) & $\begin{array}{l}\text { Las personas que ocupan el bosque (siendo } \\
\text { éstas cambiantes) }\end{array}$ \\
\hline \multirow[t]{4}{*}{$\begin{array}{l}\text { Individuos e } \\
\text { iniciativas locales }\end{array}$} & a. Buirer für Buir (BfB) & $\begin{array}{l}\text { Andreas Büttgen es la portavoz formal (una } \\
\text { iniciativa local con gente del pueblo Buir que } \\
\text { se sitúa en la ciudad Kerpen) }\end{array}$ \\
\hline & $\begin{array}{l}\text { b. Las caminatas de bosque de } \\
\text { Michael Zobel y Eva Töller }\end{array}$ & $\begin{array}{l}\text { Zobel es pedagogo forestal y Töller su pareja } \\
\text { (crean un puente entre la comunidad local y } \\
\text { los ocupantes del bosque) }\end{array}$ \\
\hline & c. Lea Heuser & $\begin{array}{l}\text { Científica de comunicación de Aquisgrán } \\
\text { (apoya la resistencia sobre todo a través de } \\
\text { relaciones públicas y su blog personal) }\end{array}$ \\
\hline & d. Beate Martin & $\begin{array}{l}\text { Mujer de } 85 \text { años de Aquisgrán (apoya la } \\
\text { ocupación donando comida, ropa y } \\
\text { ofreciendo alojamiento) }\end{array}$ \\
\hline \multirow[t]{5}{*}{ Iniciativas nacionales } & a. Ende Gelände & $\begin{array}{l}\text { Bloquean la infraestructura técnica de la } \\
\text { mina Hambach y organizan el Campo } \\
\text { Climático de Renania }\end{array}$ \\
\hline & b. Aktion Unterholz & $\begin{array}{l}\text { Anna Schönberg como portavoz (iniciativa } \\
\text { que se formó para dificultar el desalojo del } \\
\text { bosque en 2018) }\end{array}$ \\
\hline & c. Kohle ersetzen & $\begin{array}{l}\text { Parecido a "Ende Gelände" (aunque } \\
\text { independiente de esta iniciativa, su trabajo se } \\
\text { concentra en bloqueos de calles) }\end{array}$ \\
\hline & d. Alle Dörfer bleiben & $\begin{array}{l}\text { Conjunto de personas afectadas por la } \\
\text { extracción de carbón, miembros del } \\
\text { Movimiento para la Justicia Ambiental y } \\
\text { ciudadanos solidarios }\end{array}$ \\
\hline & e. BUND & $\begin{array}{l}\text { Con Dirk Jansen como portavoz (la alianza } \\
\text { ha presentado varias demandas contra RWE } \\
\text { con el objetivo de terminar la extracción de } \\
\text { lignito en la mina Hambach) }\end{array}$ \\
\hline
\end{tabular}

Aparte de estos actores, en la resistencia en el bosque participan muchas más personas e iniciativas que no podemos mostrar aquí por el espacio limitado. Se llevaron a cabo siete entrevistas entre mayo y julio del 2019 con dos personas que ocupan el bosque desde hace unos años (aquí los llamamos Ocupante $1 \mathrm{y}$ Ocupante 2), Andreas Büttgen, Beate Martin,
Lea Heuser, Anna Schönberg y una persona que fue reasentada por la extracción del lignito en su región (llamado Entrevistado 3). Aparte de esto, se usa el discurso que dieron Michael Zobel y Eva Töller en el marco de la conferencia "Defender lo sagrado"9 que tuvo lugar el 22 de mayo de 2019 en Colonia10. Después de haber realizado las entrevistas, se

9 Título original en inglés: „Defend the Sacred“.

10 Se encuentra una lista con los nombres de las personas entrevistadas, las organizaciones, el lugar y la fecha de la entrevista como anexo del trabajo. 
han clasificado sus métodos con las categorías que propone Gene Sharp (1973) de acciones no-violentas.

Como ya señalaron Kaufer y Lein (2018) el contacto con los ocupantes del bosque por correo electrónico o por teléfono es difícil. El contacto personal o una visita al Bosque de Hambach resultó ser la mejor manera de ponerse en contacto con la gente debido a que muchos ocupantes tienen miedo de la represión policial y prefieren no ser grabados. Por lo tanto, las declaraciones de los ocupantes del bosque se registraron por escrito. Las otras entrevistas, en cambio, -también el Entrevistado 3- fueron grabadas. Todas las entrevistas fueron realizadas en alemán y las declaraciones que se consideraron más importantes y pertinentes, para citar en este trabajo, fueron traducidas al español. La duración promedia de las entrevistas fue de 45 minutos.

La segunda parte de la metodología fue un análisis cualitativo de artículos periodísticos, informes de Organizaciones No Gubernamentales (ONGs), materiales audiovisuales y estudios previos sobre el Bosque de Hambach. Hasta ahora existen pocos trabajos académicos sobre el caso. Dos estudios de relevancia son el Activismo en el Bosque de Hambach- El día a día como estrategia política11 de Pfeifer, Schneider y Stadtman (2017) y el trabajo de Kaufer y Lein (2018) titulado Resistencia en el Bosque de Hambach: Un análisis de una ocupación de bosque anarquista ${ }^{12}$.

En la actualidad existe una brecha de investigación con respecto a las distintas estrategias de resistencia que se han presentado para la protección del bosque. Por ejemplo, el trabajo de Kaufer y Lein (2018) está muy enfocado en la ocupación del bosque. No se ha publicado ningún trabajo que distinga entre diversas estrategias o que estudie la efectividad de la lucha no-violenta. Este artículo intenta acercarse a esta brecha de investigación.

Durante las entrevistas y la investigación sobre la base de diferentes fuentes de información, se trataba principalmente de observar cómo se describen las estrategias de los distintos actores (violentos/no-violentos). Las atribuciones externas se comparan con las autoatribuciones y luego se compararán entre sí.

\section{Resistencia civil y noviolencia. Conceptos y vinculación con el cambio climático}

La historia de la resistencia se puede contar desde todas las latitudes y geografías donde los seres humanos han construido civilización. Ponerse en contra del status quo, de normas y leyes, desobedecer a los que ejercen el poder y reclamar la justicia, estas acciones "no solo han sido parte importante de nuestra historia sino todo un arte, sin el cual resulta difícil imaginarse el progreso humano" (López Martínez, 2016: 1).

Aunque en ciertas ocasiones parece que solo se pueden crear cambios sostenibles a través de la violencia, a lo largo de la historia se han usado también estrategias que no la requieren. Gene Sharp (1973), un politólogo nacido en Ohio en 1923, se refiere a ellas como métodos de acción no-violenta, y términos relacionados son resistencia civil o lucha noviolenta. Según Sharp (1973: 4), "La acción no-violenta es una técnica que se usa para controlar, combatir y destruir el poder de los oponentes con métodos no-violentos". Una

\footnotetext{
${ }^{11}$ En alemán: Aktivismus im Hambacher Forst - Alltag als politisches Mittel.

12 En alemán: Widerstand im Hambacher Forst: Analyse einer anarchistischen Waldbesetzung.
} 
acción no-violenta puede ser ejercida individualmente o colectivamente por un movimiento.

Estos métodos se basan en una filosofia, la satyagraha ghandiano, que busca manejar y transformar los conflictos de una cierta manera. Fue Mohandas K. Ghandi quien fundó este concepto, que va más allá del simple rechazo de la violencia armada. Se trata de una lucha para la verdad y la autorealización del colectivo en contra de falsedad, violencia y opresión (Vinthagen, 2015).

En 1973, Sharp publicó The Politics of Nonviolent Action que nos ha sido de gran utilidad para este artículo. En este libro estudia una variedad de métodos para clasificar las acciones no-violentas, documentando 198 de ellas y dividiéndolas en tres categorías ${ }^{13}$. En este artículo se usan sus elaboraciones como base para clasificar los métodos de resistencia contra la deforestación del Bosque de Hambach. Sin embargo hay que mencionar que hasta hoy en día, nuevos métodos de acción no-violenta han aparecido. En una próxima publicación para el Centro Internacional de Conflictos Noviolentos'14, el autor Michael Beer presenta una versión actualizada, ampliada y reclasificada de la lista que ofrece Sharp. Su trabajo Revisitar los métodos de acción no-violenta15, incluye una nueva categoría de acciones no-violentas llamada "intervención creativa (constructiva)". Beer (2019) la define como una "acción directa que modela o construye comportamientos e instituciones alternativas o se hace cargo de las instituciones existentes". Esta categoría es de gran relevancia para nuestra investigación a la hora de analizar la ocupación del Bosque de Hambach 16 .

Nepstad (2015) ofrece nueve categorías de acciones no-violentas ${ }^{17}$. La categoría que a nosotros más nos interesa, es la resistencia cotidiana. Fue James C. Scott (1989) quien inventó el término sin referirse al tema de la noviolencia, sino a las resistencias en general. Se define por resistencia cotidiana "prácticas ordinarias de activismo que sostienen e impulsan los movimientos sociales" (Halvorsen, 2015: 404). Los estudios al respecto -en su mayoría etnográficos- han analizado cómo se desarrolla el día a día en el activismo (Halvorsen, 2015; Chatterton y Pickerill, 2010). Nepstad explica que las personas resisten de manera cotidiana cuando otras formas de resistencia implican demasiado riesgo o cuando subvierten las estructuras opresivas a través de formas de acción en la vida diaria (Nepstad, 2015).

El siguiente párrafo sirve para conectar las acciones no-violentas con al activismo concreto, en este caso la lucha contra el calentamiento de la tierra. La sueca Greta

13 La versión original de los métodos está escrita en inglés. Por esto, hacemos uso de la traducción que ofrece Paco Cascón: http://www.noviolencia.org/publicaciones/metodos_sharp.pdf. Los números de su lista difieren un poco de la lista original. Los números que mencionamos son los de la lista original.

${ }^{14}$ En inglés: International Center on Nonviolent Conflict (ICNC).

15 En inglés: Revisiting the Methods of Nonviolent Action.

16 Dado el espacio limitado de este artículo, no podemos presentar las ideas de Beer (2019) con más detalle.

17 Las categorías son: "Everyday Resistance", "Covert Resistance", "Symbolic moral witness", "Reformist nonviolence", "Negotiated revolutions", "People power revolutions", "Electoral revolutions", "Anti-coup defense" y "Third-party intervention" (véase para una descripción más detallada Nepstad, 2015). 
Thunberg se convirtió en una de las personas clave que luchan contra el cambio climático con acciones no-violentas en la actualidad. En verano de 2018 ella decidió no ir a la escuela, si no resistir contra la crisis climática con huelgas enfrente de ella. Aparte de estas huelgas, su método más conocido son marchas. $\mathrm{Su}$ motivación se basa en el descontento con los políticos que -desde su perspectiva- no toman las medidas necesarias para enfrentar el calentamiento de la tierra. La gran atención que ella recibió en los medios conllevó al surgimiento del movimiento Fridays for Future (FfF) en agosto de 2018. En marzo de 2019, las protestas movilizaron más que 1,6 millones de personas en todo el mundo ${ }^{18}$.

Otro grupo que se hizo muy popular es Extinction Rebellion (ER), en español "Rebelión contra la Extinción". Este fue fundado por unos científicos y activistas en Gran Bretaña (GB) en octubre de 2018. Hoy existen grupos locales en más de 30 países, sus miembros usan la desobediencia civil de masas. Una red de grupos climáticos que organizan acciones directas no-violentas en Inglaterra es UK Student Climate Network (UKSCN) ${ }^{19}$.

Éste artículo se enfoca en el movimiento Hambi bleibt! de Alemania que cuenta con una participación muy diversa en cuanto a las personas y sus formas de resistir lo que mostraremos en el siguiente apartado. El análisis del movimiento puede ampliar los conocimientos frente a cómo organizarse mejor, cuáles técnicas son útiles y cómo enfrentar casos de ser criminalizados por defender el clima.

\section{El movimiento ecologista alemán y la resistencia civil contra la deforestación del Bosque de Hambach}

Alemania es conocida internacionalmente por la implementación de medidas, instituciones, programas y por aprobar leyes que deben proteger el medio ambiente. El movimiento ecologista del país se divide en dos ramas. La primera se formó durante la transición del siglo XIX al siglo XX y la segunda en los años 1970 s y 1980 s. El primer movimiento tenía sus raíces en corrientes románticas, el movimiento "seguridad para la patria"20 y la agricultura biodinámica (1924) que se basaba en los principios antroposóficos. El segundo movimiento se desarrolló como parte de los denominados Nuevos Movimientos Sociales (NMS), influidos por el cambio de valores y el apego a otros post-materialistas. En el oeste del país, nuevos programas para proteger el medio ambiente fueron establecidos, nuevas leyes fueron aprobadas y el Gobierno alemán intentó institucionalizar la política ambiental (Jänicke et al., 1999).

Las protestas que tenían lugar durante los años 1970s y 1980s, se enfocaron en la energía nuclear. Un caso importante y conocido internacionalmente, en la historia del movimiento ecologista alemán, fue el conflicto de la comunidad de Wyhl (BadenWurtemberg), en 1975, cuando miembros de 30 iniciativas ciudadanas ocuparon el terreno donde se iba a construir una planta de energía nuclear. De esta ocupación se formó luego una protesta duradera de masas con

\footnotetext{
18 En este mapa se puede ver dónde los jóvenes están resistiendo en la actualidad. También se formaron grupos de padres que resisten („Parents for Future“): https://www.fridaysforfuture.org/ statistics/map.

${ }^{19}$ Para más información véase UKSCN (2019).

20 En alemán: Heimatschutz.
} 
aproximadamente 28.000 personas. Pensamos que la resistencia civil en Whyl sirvió de antecedente al movimiento actual con sus diferencias y similitudes.

Las primeras voces críticas contra la extracción de lignito y sus consecuencias con respecto a la mina Hambach emergieron en 1977, cuando científicos jóvenes de la Universidad RWTH de Aquisgrán fundaron el Grupo de Hambach ${ }^{21}$. Su protesta fue motivada por el disgusto que causó la destrucción de varios pueblos al abrirse la mina. Las actividades de este grupo terminaron en 1990. La ocupación del bosque empezó en 2012. Esta forma de protesta se distingue claramente de las actividades del grupo mencionado anteriormente en cuanto a la visibilidad, la movilización y las formas de resistencia. Desde entonces, muchas formas distintas de protesta aparecieron contra la deforestación.

El conflicto sobre el Bosque de Hambach cuenta con una participación de actores muy diversos, por lo que hay que entenderlo desde una perspectiva multidimensional. No solo está la compañía energética alemana RWE (también conocida como RWE Power o RWE AG) en una parte, y de otro con personas, grupos e iniciativas locales y nacionales que realizan activismo. Como se explica en el Atlas de Justicia Ambiental, el conflicto es más complejo y multidimensional: también hay la representación internacional y local, partidos políticos locales y el Gobierno alemán, ciudadanos, comunidades, vecinos, movimientos sociales y también profesionales y científicos. Todas estas personas, instituciones e iniciativas hacen parte del conflicto y no siempre mantienen una posición claramente a favor o en contra del carbón y la deforestación del bosque.

\subsection{El Bosque de Hambach y la mina Hambach}

El Bosque de Hambach fue una masa forestal de aproximadamente 5.000 hectáreas (la información difiere según la fuente), pero ahora mismo la superficie es de solo 200 hectáreas. Desde 1972 pertenece a la municipalidad Niederzier, en el distrito de Düren en Renania del Norte-Westfalia. La mina de carbón a cielo abierto Hambach es propiedad de la empresa RWE que fue fundada en 1898, la cual agrupa la industria de electricidad a partir de lignito y energía nuclear. Tiene su sede en Essen (Alemania) y su presidente actual es Dr. Rolf Martin Schmitz.

La mina a cielo abierto de Hambach está situada entre las ciudades Jülich y Kerpen y ocupa 85 kilómetros cuadrados, de los cuales por ahora se está explotando la mitad, y tiene una profundidad de 370 metros. Según RWE, la mina cuenta con 2.500 millones de toneladas de lignito hasta una profundidad de 450 metros de donde se extraen 40 millones de toneladas anuales. Su lignito suministra energía a la industria del estado federal de Renania del Norte-Westfalia (La Vanguardia, 2018; Scheidel, 2015).

${ }^{21}$ En alemán: Hambach Gruppe. 
IMAGEN 1. LA REGIÓN MINERA DE RENANIA (EN ALEMÁN: RHEINISCHES BRAUNKOHLEREVIER. FUENTE: THOMAS RÖMER, SEPTIEMBRE DE 2018 Y ELABORACIÓN PROPIA)

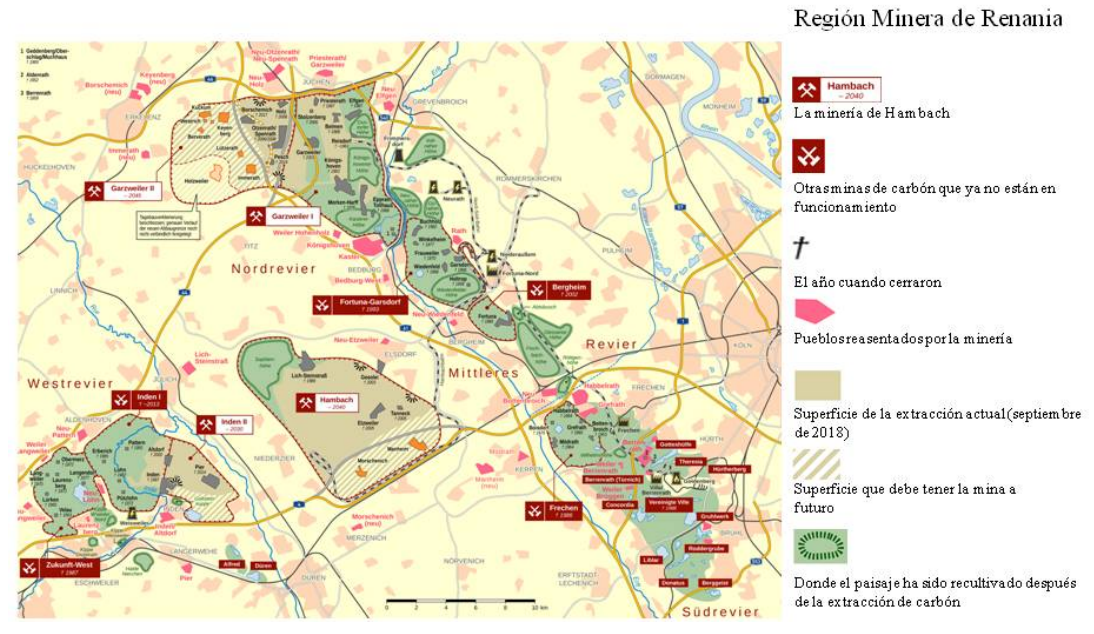

RWE produce cerca de 100 millones de toneladas de esta materia prima por año y emplea a unas 10.000 personas. De una pequeña parte de las briquetas de carbón crudo, se generan polvo de lignito, carbón de leña fluido y coque para uso doméstico e industrial. Alrededor del $90 \%$ se convierten directamente en electricidad desde el propio lugar (RWE, 2019; Scheidel, 2015). En la imagen 1 se puede ver, dónde se ubica la mina Hambach en la Región Minera de Renania. La imagen 2 fue tomada el 30 de agosto de 2018 y demuestra la cercanía entre el bosque y las excavadoras de la mina en este momento.

Para extraer el carbón, el agua subterránea es drenada desde 1976. Este drenaje se realiza hasta profundidades de 550 metros. Pasarán siglos antes de que las condiciones naturales del agua subterránea se restablezcan después de que las actividades mineras hayan finalizado (BUND NRW, 2019a; Töller, 2019).

El Atlas de Justicia Ambiental enumera entre otros los siguientes impactos visibles que genera la extracción de carbón y la tala del bosque para el medio ambiente: contaminación del aire, pérdida de la biodiversidad, calentamiento de la Tierra, contaminación de las aguas superficiales y disminución de su cantidad (fisicoquímica, biológica) (Scheidel, 2015).

\section{IMAGEN 2. LA MINA HAMBACH A LA DERECHA Y EL BOSQUE DE HAMBACH A LA IZQUIERDA (FUENTE: MICHAEL GOERGENS, 30.08.2018)}

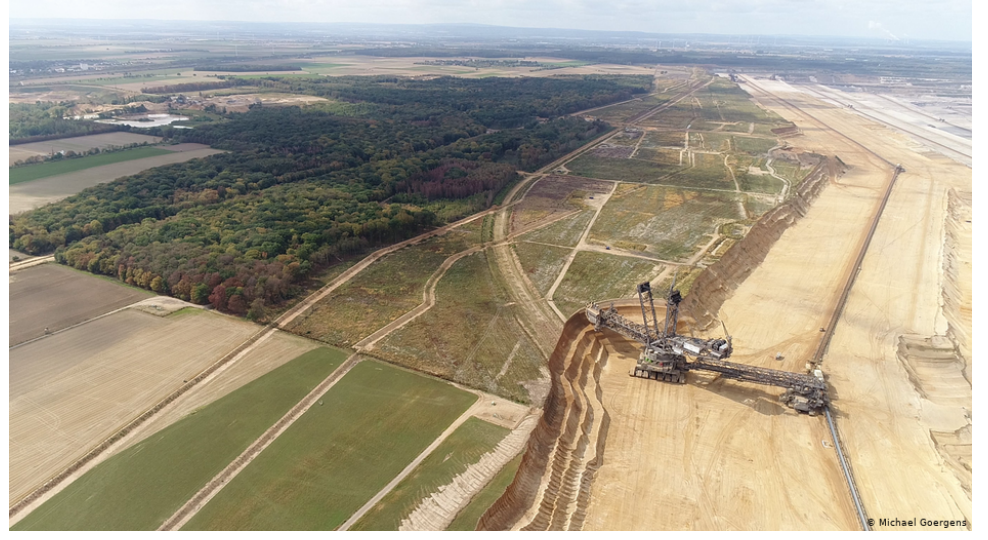


Como resultado de las actividades extractivas de RWE, varias comunidades tuvieron que ser reasentadas: hasta el año 2014, 3.000 personas ya tuvieron que mudarse de manera forzada y hasta 2030, el número podría subir a 5.200 personas (Scheidel, 2015). En alemán, se llama a estos lugares, sin habitantes, pueblos fantasmas. El documental "La Línea Roja"22, recoge el testimonio de Lars Zimmer, un habitante de la localidad de Immerath que se está resistiendo mientras que todos sus vecinos ya se han desplazado.

\subsection{La legislación}

En 1974 la antigua empresa Rheinbrau AG (ahora RWE) inició el procedimiento de aprobación para la minería a cielo abierto Hambach, luego compró el terreno donde está situado el Bosque de Hambach y los alrededores. Las primeras excavadoras empezaron a extraer el carbón el 17 de enero de 1984. El contrato entre RWE y el Gobierno está vigente hasta 2040. Sin embargo, esta fecha está puesta a debate como verémos más adelante.

En diciembre de 2015, Alemania firmó junto con otros 194 países el primer acuerdo vinculante mundial sobre el clima, conocido como el Acuerdo de París en la Conferencia de París sobre el Clima (COP21). Esta firma global se comprometió a adoptar medidas para reducir la temperatura de la Tierra al menos de dos grados. Para alcanzar esta promesa, el Gobierno Federal de Renania del Norte-
Westfalia (en su abreviatura alemana: NRW) creó en 2018 la comisión Desarrollo, Cambio de Estructura y Empleo23, también conocida como Comisión del Carbón. Su tarea consiste en proponer acciones concretas para el abandono de fuentes energéticas no-renovables $\mathrm{y}$ crear puestos de trabajo en el futuro que reemplacen los que se verán afectadas por el cambio estructural.

En enero de 2019 la Comisión del Carbón presentó un plan integral24 sobre cómo salir gradualmente de la energía del carbón y pasar a la energía renovable. Recomienda el año 2038 como fecha límite para dejar de explotar esta materia prima (BMWi, 2019). Además, incluye una cláusula abierta en la que si el mercado de electricidad, el laboral y la situación económica lo permite o lo exigen, la fecha puede adelantarse a 2035 de acuerdo con los operadores. En 2032, no obstante, todo esto será evaluado.

En el caso de que Alemania siga extrayendo el carbón hasta 2035 o 2038, el país no podrá contribuir a reducir el aumento de temperatura del planeta en dos grados. A esta conclusión llegó la organización británica Carbon Brief en un análisis que fue publicado en enero de 2019. De ello se deduce que, el cronograma recomendado de la Comisión del Carbón, es insuficiente. Los investigadores comentan que las centrales eléctricas de carbón de Alemania representan más de una cuarta parte de las emisiones nacionales de $\mathrm{CO} 2$ y el $7 \%$ del total de la Unión Europea (UE) (Evans, 2019). Aquí se manifiesta el papel importante

\footnotetext{
22 El título original en alemán es "Die Rote Linie". La directora es Karin de Miguel Wessendorf y la fecha de publicación fue el 23 de mayo de 2019. Se puede ver el tráiler en alemán aquí: https:// www.youtube.com/watch?v=o-AFrWR1TyY.

${ }^{23}$ En alemán: Wachstum, Strukturwandel und Beschäftigung (WSB), abreviatura: Kohlekomission.

${ }^{24} \mathrm{El}$ informe de la comisión se encuentra bajo este enlace (en alemán): https://www.bmwi.de/ Redaktion/DE/Downloads/A/abschlussbericht-kommission-wachstum-strukturwandel-undbeschaeftigung.pdf?_blob=publicationFile \&v=4.
} 
que juegan los procesos de resistencia civil contra la deforestación del Bosque de Hambach y contra las actividades de la mina. Los efectos de la extracción de lignito en Alemania se sienten en todo el mundo, como muestra por ejemplo la historia del campesino peruano Luciano Lliuya 25.

El Bosque de Hambach ha sido desalojado varias veces desde su primera ocupación en el año 2012. Este artículo se concentra en el desalojo que ocurrió en septiembre de 2018. Esta evacuación fue ordenada por el Gobierno de NRW, basada en los requisitos de la Ley de Construcción. La ministra del Ministerio de la Patria, Asuntos Municipales, Construcción e Igualdad del Estado de Renania del Norte-Westfalia ${ }^{26}$ Ina Scharrenbach estableció, mediante Decreto, que las casetas de madera en los árboles eran instalaciones no sujetas a la normativa de construcción $\mathrm{y}$, sin cumplir medidas de seguridad contra incendios, no podrían ser habitadas sino derruidas (Wernicke, 2018). Luego, el periodista Christian Parth (2019) reveló que el ministerio estaba colaborando con la empresa energética para poder desalojar el bosque.

El desalojo se inició el 13 de septiembre de 2018 mediante la Fuerza de Tarea Especial de la Policía (abreviatura en alemán: SEK). Como resultado de los procesos de resistencia, el Tribunal Superior Administrativo de Münster (abreviatura en alemán: OVG) ordenó la suspensión temporal de desalojo del Bosque de Hambach el 5 de octubre de 2018, una decisión que el Tribunal tomó amparado en normativas europeas que protege hábitats naturales de especies de flora y fauna (BUND NRW, 2019b).

En el siguiente apartado se describirán los actores más importantes de la resistencia civil, su forma de organización, sus motivos y estrategias. Por su popularidad, vamos a explicar la ocupación en detalle mientras que presentamos a los otros actores con menos profundidad.

\subsection{Los actores (organización, motivos y estrategias)}

\subsubsection{La ocupación del bosque}

La estrategia más conocida para defender el Bosque de Hambach ha sido la ocupación del bosque con casas-árbol que se sitúan a unos 10 a 15 metros de altura y estructuradas en pequeños barrios. Éstos son independientes unos de otros, pero realizan reuniones comunitarias. La ocupación empezó en 2012, unos días antes de la junta general anual de RWE, durante una fiesta cultural que tenía el siguiente lema: "Bosque en vez de Carbón" (Hambacherforst, 2015). Antes del desalojo en 2018 había aproximadamente 50 casas-árbol que contaban con una infraestructura notable, de varias plantas, con cocinas y hasta almacenes. También había un

\footnotetext{
25 Véase Müller (2017) para conocer la historia de Luciano Lliuya que vive en la provincia Ancash y quien acusó a la empresa RWE de ser responsable del 0,47\% de todas las emisiones de CO2 en el mundo.

26 En alemán: Ministerium für Heimat, Kommunales, Bau und Gleichstellung des Landes Nordrhein-Westfalen.
} 
programa de radio del Bosque de Hambach (método 1127), unas casas llevaban paneles solares, había duchas y baños secos.

Parte de la ocupación formó el "Campamento de pasto"28. Pfeifer et al. (2017) lo describen como un campamento base de la ocupación que sirvió para organizarse y recargar las energías para el día a día en el bosque, razón por la cual cumplió un papel clave para sostener la ocupación ${ }^{29}$.
Es importante mencionar que no se puede clasificar, fácilmente, a los ocupantes. En su página web aclaran que: "No somos una organización formal, sino una asociación de individuos libres" (Hambacherforst, 2019), por tanto, hay personas que tienen estilos de vida y trabajos muy diversos (Hambacherforst, 2019), si bien la mayor parte de ellos se ubica en un umbral de edad entre los 20 y los 35 años.

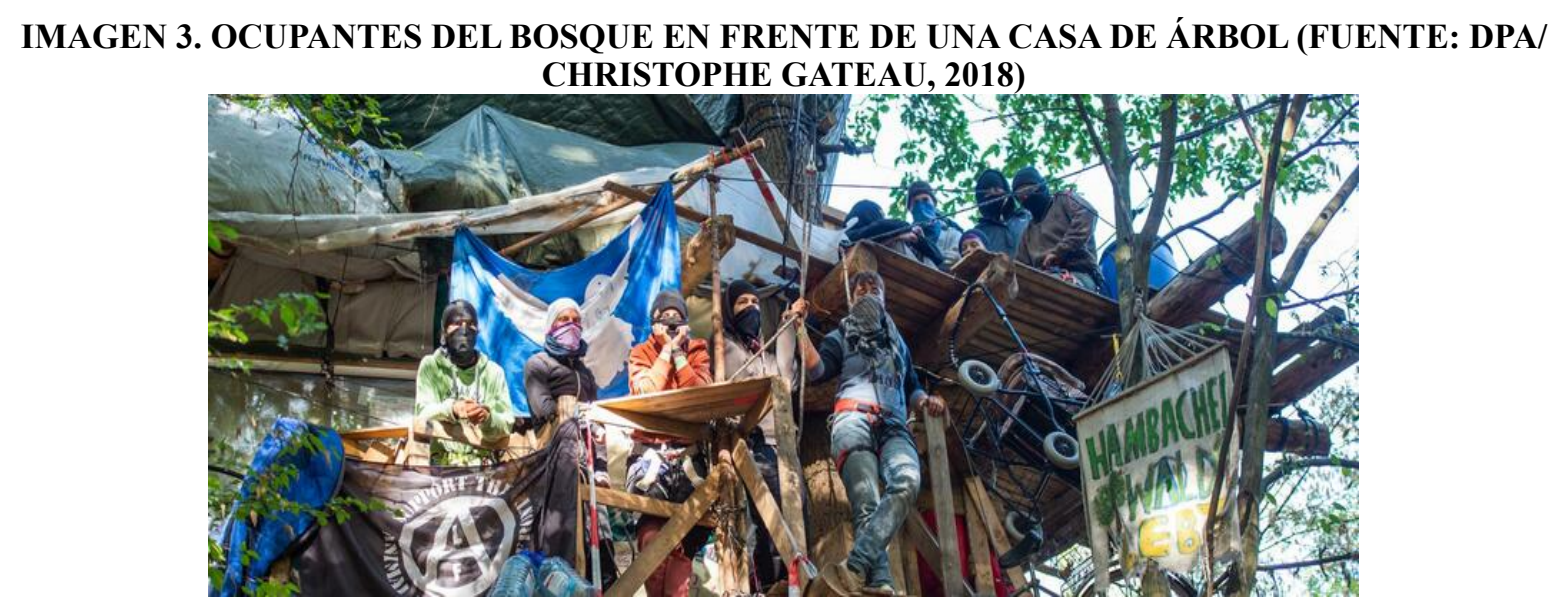

Los motivos para ocupar el bosque son muy numerosos, pero el objetivo central que comparten es la protección del bosque y el medioambiente, oponerse al capitalismo y al desarrollo centrado en el crecimiento económico (Pfeifer et a1., 2017 ; Hambacherforst, 2015). Para muchas personas también se trata de experimentar una forma de vida alternativa.

En un libro publicado por los ocupantes, ellos explican por qué eligieron esta forma de protesta: primero, porque existe un abismo demasiado grande entre lo legal y lo que nosotros consideramos legítimo. Si RWE decide destruir el bosque para extraer carbón y si a través de esto destruye los medios de subsistencia (...) el clima del mundo (...) es jurídicoestatalmente legal. (...) Si nosotros ocupamos el bosque, no es legal. La acción recibe su legitimidad por el hecho de que intenta ser un poder en

27 En comillas se encuentran los métodos de acción noviolenta que se han usado para proteger el Bosque de Hambach clasificados según la lista de Gene Sharp de 1973. Se puede encontrar la lista completa en inglés bajo este enlace: https://www.brandeis.edu/peace-conflict/pdfs/198-methodsnon-violent-action.pdf.

${ }^{28}$ En alemán: Wiesencamp.

29 Aunque el pasto está en la propiedad de un particular, se considera ilegal porque viola la ley de construcción (Aachener Zeitung, 2017). 
contra de la destrucción (...) de RWE (Hambacherforst, 2015).

Para protegerse contra la represión policial, muchos ocupantes esconden su identidad o usan seudónimos. Aparte de esto, las personas usan pasamontañas $\mathrm{u}$ ocultan sus caras con máscaras como se puede observar en la foto.

Referido al anterior comentario, se puede decir que los ocupantes hacen uso de alternativas ciudadanas a la obediencia, un ejemplo de no cooperación política, en especial el método 140 (esconderse, escaparse o toma de falsas identidades). También tiene que ver con el método 129 (rechazar ayudar a los agentes gubernamentales a través de no darles información). Podemos clasificar la ocupación como una institución alternativa según Beer (2019). Desconcentrar o difundir el poder entre varios grupos y descentralizar las estructuras del movimiento, es un objetivo de la construcción de instituciones alternativas. Otro objetivo es capacitar a las personas y facilitar la toma de decisiones democráticas basadas en un consenso o compromisos negociados. En el bosque, decisiones que son de relevancia también se toman por consenso (Pfeifer et al., 2017).

Seguimos las ideas de Scott (1989) cuando clasificamos la ocupación como una forma de resistencia cotidiana. Para él, las resistencias cotidianas se legitiman por su alto contenido simbólico, que le da a dichas resistencias su fuerza. Ello se refleja en lo siguiente: Los ocupantes viven y experimentan una utopía social, una convivencia libre de dominios, solidaria y autónoma. Se organizan sin líderes y su forma de vida es casi autosuficiente. La ocupación también encaja con las ideas que brinda Beer (2019) sobre la creación de instituciones alternativas. Según él, las instituciones buscan construir un modelo de cambio basado en la transformación social, la autoorganización, la liberación y la prefiguración. La infraestructura que existe en el bosque (cocinas, baños, espacios para discutir) también es algo típico de instituciones alternativas ${ }^{30}$. Los ocupantes se comunican con el público a través de muchos afiches, carteles y banderolas (método 8).

Pensamos que entre los 5 tipos de instituciones alternativas que ofrece Beer (2019), la ocupación en el bosque se puede identificar mejor con el tipo 4 (Autoorganización y autonomía) y 5 (Autosostenibilidad). El primer objetivo de autosostenibilidad es asegurar una ocupación de un espacio específico simbólico que normalmente dura un tiempo limitado, en este caso, el espacio es el bosque. Durante el transcurso del tiempo, el Bosque de Hambach se convirtió en un símbolo político de lo cual ahora distintos actores políticos hacen uso. Ahí radica el amplio potencial de movilización nacional para los activistas dentro y alrededor del bosque (Bunnen, 2019).

Durante el día a día, los ocupantes organizan acciones directas y ofensivas, como el sabotaje de la conducción de corriente eléctrica principal de la mina de Hambach. Como resultado de esta acción, la corriente dejó de funcionar por 24 horas (Kölner Stadtanzeiger, 2016). Con respecto a Gene Sharp, esta acción se podría establecer como una modificación de un boicot económico realizado por consumidores (método 71).

30 Construcciones similares se pudieron apreciar durante las protestas enmarcadas en la Primavera Árabe en Egipto (de enero a febrero de 2011, la plaza Tahrir se llenó de tiendas de campaña, clínicas de salud, servicios de recolección de basura y baños públicos), y algo similar sucedió en mayo de 2011 con el movimiento 15-M en España. 
Aunque el debate está siempre servido, interpretamos que se trata del uso de fuerza contra bienes materiales pero no de violencia hacia personas, por tanto son acciones noviolentas.

Aunque hemos visto que los ocupantes hacen uso de distintos métodos de acción noviolenta, las entrevistas que se realizaron con ellos mismos y las otras personas que resisten demuestran que no toda la gente en el bosque se opone claramente a la violencia directa. Por la diversidad de las personas que realizan la ocupación, sus motivos y estrategias, resulta difícil aclarar quiénes prefieren actuar sin o con violencia directa. Beate Martin y Lea Heuser a quienes presentamos más adelante, comentan que la mayoría de las personas del movimiento es pacífica, pero reconocen que algunas sí usan violencia. Como explican ellas, nunca se sabe realmente quiénes son y si realmente son personas que viven en el bosque o si solo están ahí vienen por unos días.

A pesar de ello, los actos violentos no han disminuido su nivel de solidaridad con los ocupantes. Esto es interesante en el marco de la hipótesis de que las personas locales se podrían dejar lejitmar la ocupación debido a la violencia y distanciarse. Andreas Büttgen explica que, aunque hay personas en el bosque que realizan acciones de violencia directa, hay un nivel alto de valor cívico entre otros ocupantes: "Hay gente que dice: 'dejen esto, no lo queremos'. Pero, de esto no hay información" (Büttgen, 2019).

Hasta hoy en día, se han vivido cuatro ocupaciones. Durante cada ocupación, muchas personas nuevas se sumaron al movimiento de protección del bosque. Durante el cuarto desalojo que tuvo lugar en otoño de 2018, más de 50 casas-árbol fueron destruidas, así como barricadas y otro tipo de infraestructura de ocupación. Las casas-árbol que se pueden encontrar actualmente31 fueron en su mayoría construidas por nuevos activistas, que no habían hecho parte de la ocupación que existía antes del otoño 2018.

\subsubsection{Apoyo local}

Una característica importante de la resistencia es la cooperación entre los ocupantes del bosque con individuos e iniciativas locales. Como explica Büttgen (2019), el apoyo local refuerza a los ocupantes y Pfeifer et al. (2017: 2) añaden:

\section{El apoyo local es esencial para la preservación de la ocupación, ya que los ocupantes reciben apoyo de ellos (...). El conocimiento de la solidaridad de partes de la población local alienta a los activistas.}

\section{Buirer für Buir 32}

Un ejemplo importante a nivel local es Buirer für Buir (BfB). Una simple iniciativa ciudadana que, más tarde, se convirtió en una asociación. Sus miembros quieren garantizar una buena calidad de vida para las personas que viven en Buir y otros pueblos mineros y mostrar los impactos negativos que produce la extracción del carbón. De ahí surgió la conexión con la protesta en el Bosque de Hambach (Büttgen, 2019). Andreas Büttgen es el portavoz formal de la asociación. Otra persona popular de BfB es Antje Grothus quien, además, hace parte de la Comisión del Carbón donde representaba la resistencia contra la deforestación del Bosque de Hambach.

\footnotetext{
${ }^{31}$ Aquí nos referimos a noviembre de 2019.

32 Significado: Habitantes de Buir para Buir. Buir es el nombre del pueblo.
} 
Los miembros de BfB usan estos métodos de acción no-violenta de acuerdo a la tipología de Sharp (1973):

- Método 3 (declaraciones de organizaciones e instituciones) y 5 (declaraciones de acusación e intenciones): a través de redes sociales se comunican con otros actores, apoyan a otras organizaciones ambientales e individuos y publican declaraciones y quejas contra RWE, el Gobierno alemán y la policía.

- Método 38 (manifestaciones)

- Método 45 (entierros demostrativos): los miembros de $\mathrm{BfB}$ realizaron el acto simbólico de enterrar la salud y la democracia

- Método 48 (encuentros de protesta): reuniones entre los miembros de BfB para discutir sobre sus objetivos

- Método 50 (foros de información): el uso de los redes sociales, organización de eventos informativos

\section{Caminatas por el Bosque}

El pedagogo forestal Michael Zobel y su pareja Eva Töller organizan caminatas, todos los domingos desde 2014, por el Bosque de Hambach. De esta manera quieren mostrar la importancia de esta masa forestal, su biodiversidad y quieren reconstruir la relación del ser humano con la naturaleza. Cada persona que quiere conocer el bosque puede participar, independiente de su edad. De tal forma, los paseos se han transformado en una posibilidad de resistencia que se enfoca en el intercambio de conocimientos y de crear aceptación para distintas formas de resistencia.

Hay dos objetivos clave en las caminatas: en primer lugar, Zobel y Töller quieren mostrar imágenes a las personas que normalmente no ven. "La mayoría de la gente no va al bosque, no sabe si se puede entrar (...) entramos y mostramos que también este bosque pequeño debe ser protegido porque es especial (...)" (Zobel, 2019). El segundo objetivo es crear relaciones y enlaces entre diferentes personas, sobre todo entre la gente local y los ocupantes (Pfeifer et al., 2017; Büttgen, 2019; Schönberg, 2019).

Podemos clasificar las caminatas según Gene Sharp de la siguiente manera:

- Método 38 (manifestaciones)

- Método 40 (procesiones religiosas)

- Método 41 (peregrinaciones)

- Método 36 (actuaciones de obras de teatro y música): intervenciones con música durante las caminatas- por ejemplo del músico Klaus der Geiger

Las caminatas en el bosque tienen un carácter religioso-espiritual, pues también hay ceremonias y vienen personas que defienden un así llamado activismo sagrado. Esto ocurrió, por ejemplo, el 21 de mayo de 2019 cuando Ladonna Bravebull Allard33 y Sabine Lichtenfels realizaron un ritual indígena para apoyar a la protección del bosque34. Ahí también se hace uso del método 20 de Sharp (Oración y Adoración).

\section{Lea Heuser}

33 Se trata de una activista indígena que luchó contra la Dakota Access Pipeline en los Estados Unidos. Las protestas empezaron en 2016.

34 El enlace para el evento se encuentra aquí: https://www.facebook.com/events/ $2655723661111481 /$. 
Lea Heuser tiene 38 años, es científica de la comunicación, la portavoz de prensa de la asociación Premio de Paz de Aquisgrán y desde enero de 2019 es la gerente de la Casa del Mundo Aquisgrán 35 . Decidió participar en la resistencia a principios de 2016. Ella es ciega y por esto, no puede participar en muchas otras formas de protesta (por ejemplo manifestaciones de masa).

Antes de dar sus aportes para ¡Hambi bleibt!, Lea Heuser hizo parte del movimiento alemán por la paz ${ }^{36}$ donde todavía interviene. En cuanto al activismo por el bosque, participó primero en las caminatas organizadas por Michael Zobel (métodos 38, 40 y 41) y en las manifestaciones de la línea roja37. Luego empezó a escribir artículos en favor de la resistencia que publica en su blog personal 38 (métodos 2, 10 y 179). De esta manera, crea más atención sobre el caso.

\section{Beate Martin}

Beate Martin es una mujer de 85 años que vive en Aquisgrán, población ubicada a 40 kilómetros del Bosque de Hambach, y que apoya la ocupación del bosque a nivel local. Con su resistencia quiere actuar contra la destrucción de la naturaleza y se preocupa por los efectos que tiene la extracción de carbón en la salud y las personas que tienen que reasentarse por este motivo.

Ella apoya la resistencia cotidiana en el bosque principalmente con comida $y$ donaciones de ropa. Martin cuenta que, antes del desalojo que tuvo lugar en 2018, las casas contaban con una buena infraestructura y que esta fue destruida por la policía. La comida que ella cocina es vegana y la ropa que dona es de segunda mano. Compra los ingredientes o los recibe de personas de su entorno. También lava la ropa o la lleva a tiendas donde la lavan. Martin explica que a veces los ocupantes necesitan una pausa de la ocupación, porque están cansados, necesitan hablar con un médico o porque solamente quieren recargar su energía. A estas personas, les ofrece alojamiento por unos días.

Las tres navidades pasadas, Martin invitó a los ocupantes, parientes y personas de comunidades cercanas a celebrar en su casa (Martin, 2019). El apoyo de la mujer es importante para mantener la ocupación y la resistencia cotidiana. Sus aportes representan el respaldo de la comunidad local frente a la ocupación. Aparte de esto, sus actividades están relacionadas con el método 190 de Sharp (mercados alternativos).

35 La Casa del Mundo (en alemán: Welthaus) en Aquisgrán cuenta con el apoyo de 19 organizaciones e iniciativas en los campos de la política ambiental y de desarrollo, así como el asesoramiento familiar y las economías alternativas.

36 En alemán: Friedensbewegung.

${ }^{37}$ Las manifestaciones bajo la Línea Roja (en alemán: Die Rote Linie) empezaron en 2016 y tratan de visibilizar el límite máximo hasta dónde RWE debe talar el bosque. Las personas llevan ropa roja y forman una frontera con sus cuerpos para marcar la línea. Se organiza por BUND, BUNDjóvenes (BUNDjugend), Greenpeace, La Alianza para el Clima Alemania (Klima-Allianz Deutschland) y la Alianza de Protección del Medio Ambiente Alemania (Naturschutzbund Deutschland, NABU). Se puede ver una de estas acciones aquí (minuto 1:05- 1:13): https://www.youtube.com/watch? $\mathrm{v}=\mathrm{tmT} 4 \mathrm{VC} 4 \mathrm{jK} 9 \mathrm{I}$.

38 Enlace de su blog personal: https://kommunikatz.wordpress.com/. 


\subsubsection{Apoyo nacional}

Ende Gelände

El periódico Taz tituló un artículo (27 octubre 2018) como Mil veces desobediencia civil con una foto de personas en monos blancos, pelucas de colores y caras felices (método 140- escapar, mostrar una identidad falsa). El artículo trata de activistas del grupo Ende Gelände 39 que había llamado a bloquear las excavadoras en la minería a cielo abierto Hambach y a ocupar las vías entre la mina y la central eléctrica. Ende Gelände entiende sus bloqueos como una acción de desobediencia civil para la protección del clima.

El grupo es activo desde 2015 y basa su resistencia en acciones en masa de desobediencia civil. Su estrategia más popular es bloquear y ocupar la infraestructura de la mina de Hambach (vías, caminos, excavadoras) para así evitar la extracción de carbón por el tiempo más dilatado posible. Podemos clasificar sus métodos con respecto a Gene Sharp así:

- Método 2 (cartas de oposición): a través de Facebook, etc.

- Método 3 (declaraciones de organizaciones)

- alternativa del método 11 (comunicación con una audiencia amplia): videos y fotos que suben a los redes sociales

- Método 141 (desobediencia civil de leyes "ilegítimas")

- Método 162 (sentadas)

- Método 170 (invasiones no-violentas)
- Método 173 (ocupaciones noviolentas- después de invadir, no salirse, sino quedarse)

- Método 183 (intervención económicainvasión de tierras en forma noviolenta): Por el tiempo que los miembros de Ende Gelände bloquean las maquinas, la empresa RWE no puede extraer carbón y sufre un daño económico

Los miembros actúan bajo un consenso de acción ${ }^{40}$. Herramientas para extender el bloqueo pueden ser por ejemplo llamados lockons $^{41}$ o hamacas. Desde 2018, Ende Gelände moviliza para campamentos climáticos $\mathrm{y}$ acciones de justicia ambiental en toda Europa con su campaña Ende Gelände Goes Europe (EGGE) ${ }^{42}$. En este artículo se considera a los campamentos climáticos como una forma de construcción de instituciones alternativas basándonos en las ideas de Beer (2019).

\section{Aktion Unterholz}

La alianza Aktion Unterholz 43 es un conjunto de grupos ambientalistas regionales de Colonia, Bonn y Aquisgrán y grupos de la izquierda radical. También han estado en contacto con otros actores nacionales como Ende Gelände. Pero por el hecho de que las intervenciones de Aktion Unterholz duraban varias semanas durante el desalojo del bosque en 2018 y las de Ende Gelände solo unos días, no cooperaban, pero se complementaban.

Los miembros empezaron sus actividades en agosto de 2018. El objetivo principal de

\footnotetext{
39 Significado del nombre: Fin de la escena.

40 En alemán: Aktionskonsens. El consenso de acción de Ende Gelände en español se puede encontrar aquí: https://www.ende-gelaende.org/es/accion/consenso_accion/.

${ }^{41}$ Lock-ons es una manera de encadenarse a objetos diversos (p.e. a un árbol, una vía de trenes).

42 Entre ellos encontramos la acción de Code Roode contra gas natural en la ciudad Groningen en Holanda o las protestas de Limity jsme my contra la extracción de lignio en la República Checa. 43 Significado del nombre: Acción de la mata / acción clandestina.
} 
Aktion Unterholz era mantener el bosque. La portavoz de la prensa de Aktion Unterholz, Anna Schönberg (2019), explica: "Quería liberarles de la sensación de que no podían hacer nada."

Los miembros actúan bajo un consenso de acción ${ }^{44}$. En septiembre de 2018, ellos desobedecieron a la policía cuando quisieron evacuar el bosque. Los métodos de acción noviolenta que usa Aktion Unterholz se dejan clasificar como:

- Método 8 (comunicarse a través de banderolas, carteleras, cartones) y Método 9 (publicar libros, folletos, etc.): en su página web se puede descargar material para movilizarse y han publicado un informe que trata de la resistencia en el bosque bajo el título Mama, ¿ésta planta también?45

- Método 129 (negar asistencia a los agentes coactivos del Gobierno)

- Método 140 (desobediencia civil contra leyes "ilegítimas")

- Método 150 (no cooperación por unidades del Gobierno constituido)

- Método 170 (invasión no-violenta)

\section{Alle Dörfer bleiben 46}

Se trata de una alianza nacional de personas afectadas por la extracción de carbón, miembros del movimiento para la justicia ambiental y ciudadanos solidarios. Su objetivo principal es proteger a los pueblos que se encuentran cerca de las minas de carbón y sus habitantes. La alianza formula cuatro demandas 47 al Gobierno alemán y a los Gobiernos de NRW, Brandeburgo, Sajonia y Sajonia-Anhalt. A ellos les parece importante que, las personas que viven cerca de las minas, tengan una buena calidad de vida. De acuerdo a esto, demandan al Gobierno federal de que establezcan límites mínimos entre los pueblos y las minas a cielo abierto (Alle Dörfer bleiben, 2019).

Para alcanzar sus objetivos, la iniciativa hace uso de distintos métodos, por ejemplo organizan días de acción ${ }^{48}$. El último día tuvo lugar el 22 de junio de 2019 bajo el lema “¡Acabar con el carbón! ¡Salvar el clima y los pueblos!"49. En la jornada participaron jóvenes de FfF y las alianzas nacionales Campact, BUND, Greenpeace y Amigos de Naturaleza Alemania 50.

Clasificamos los métodos de la alianza de la siguiente manera:

- Método 1 (discursos públicos): organizan eventos de información

- Método 7 (símbolos, frases cortas) y 8 (banderolas, carteleras, cartones): durante las acciones, las personas llevaban trajes amarillos y se podían ver cruces amarillas de madera en forma de $\mathrm{X}$ alrededor de las acciones

- Método 36 (actuaciones de obras de teatro y música): programación musical durante el día

44 El consenso de acción de Aktion Unterholz se encuentra aquí (en alemán): https://aktionunterholz.org/aktionskonsens/.

45 En alemán: “Mama, dieser Stock auch?”.

46 Significado en español: Todos los pueblos se quedan.

47 Se puede encontrar las demandas detalladas (en alemán) aquí: https://www.alle-doerferbleiben.de/wp-content/uploads/2019/06/ADB_Forderungen.pdf.

48 En alemán: Aktionstage.

${ }^{49}$ En alemán: „Kohle stoppen! Klima \& Dörfer retten!“‘.

50 En alemán: Natur Freunde Deutschland. Se trata de una alianza política para la protección del medio ambiente que cuenta con 70.000 miembros. 
- Método 38 (marchas): durante el último día de acción había una manifestación a lo largo del borde de la mina de lignito y una movilización en bicicletas

- Métodos 170 (invasión no-violenta) y 161 (sentadas): durante el día tuvo lugar la acción "Tomar asiento contra el carbón" donde miles de personas se sentaron entre los excavadores de la mina Garzweiler

\section{Kohle ersetzen}

El grupo de acción Kohle ersetzen ${ }^{51}$ se creó en 2017 y apoya a la justicia ambiental global con varias acciones de desobediencia civil, las cuales van en contra de la extracción de carbón. En su página web señalan que quieren ayudar a las personas que más van a sentir el cambio climático, pero que están invisibilizadas. También explican que sus acciones son necesarias por la urgencia de actuar y promover la justicia generacional, es decir, tomar la responsabilidad de crear una alta calidad de vida para las generaciones próximas. Dicen que sus acciones crean un puente entre las manifestaciones de la Línea roja que habíamos mencionado arriba y Ende Gelände (Kohle Ersetzen, 2019). David Dresen cuenta: "Hemos tenido mucha esperanza en la Comisión del Carbón, pero nos desilusionó porque nuestras demandas no se escucharon, así que no nos queda otra que ir un paso más allác (David Dresen citado por Kohle Ersetzen, 2019).

Sus acciones de resistencia se enfocan en
- Método 6 (peticiones en grupo o masivas): colección de firmas para presionar una salida más pronta del carbón

- Método 7 (símbolos, frases cortas) y 8 (banderolas, carteleras, cartones): en la página web, se puede descargar material de movilización como pegatinas, folletos $\mathrm{o}$ carteles gratis

- Método 38 (marchas): las manifestaciones de la línea roja con el color distintivo rojo de bloqueo

- Métodos 141 (desobediencia civil contra leyes "ilegítimas"), 170 (invasión noviolenta) y 173 (ocupación no-violenta): organizan viajes en bicicleta, durante un tour que tenía lugar en julio 2019, los ciclistas recorrieron una distancia de 800 kilómetros para llegar a la Región Minera de Renania; ahí, ellos visitaron el campamento climático de Renania y llamaron a bloquear la infraestructura de las minas de lignito en la zona

- Método 161 (sentadas)

\section{BUND}

La resistencia de $B U N D^{52}$ contra la deforestación del Bosque de Hambach se basa principalmente en la lucha jurídica. Su objetivo es mantener el bosque, cuidar el medio ambiente y proteger las especies en peligro de extinción. Por sus demandas, la tala del bosque fue detenida en octubre de 2018. Actualmente están liderando varias demandas contra RWE ante los tribunales, intentando determinar la extracción de lignito en la mina Hambach.

Dado que RWE tenía permitida la explotación hasta el 31 de diciembre de 2020,

51 Significado en español: Reemplacer el carbón.

52 Ya habíamos hablado de la alianza, en español se llama Liga Alemana para la Protección del Medio Ambiente y de la Naturaleza. 
tuvo que presentar al Gobierno del distrito de Arsnberg un plan operativo básico para renovar el permiso entre los años 2020 y 203053. El Gobierno local aprobó la solicitud el 12 de diciembre de 2014. Aquí se presentó la primera acción legal de BUND que demandó la decisión ante el Tribunal Administrativo de Colonia el 2 de marzo de 2015. Este tribunal falló a favor de la empresa y los demandantes apelaron ante el Tribunal Superior Administrativo de Münster, el cual finalmente dio la razón a BUND.

Tras haber obtenido un resultado favorable, BUND emprendió una segunda acción legal dirigida en contra del plan operativo principal, el cual había sido aprobado por el Gobierno de Arnsberg el 29 de marzo de 2018 que sugería la realización inmediata. El 20 de abril del 2018, entonces, BUND demandó otra vez la decisión del Gobierno local. Nuevamente en la segunda instancia fue el Tribunal Superior Administrativo (abreviatura en alemán: OVG) de Münster el que dio la razón a BUND. Y como ya explicamos, ordenó la suspensión temporal de la deforestación del Bosque de Hambach el 5 de octubre de 2018.

El OVG Münster basa su decisión en la importancia que tiene el Bosque de Hambach para el sistema ecológico. Como mencionamos antes, el bosque es hogar para especies que están en peligro de extinción. Hay que aclarar si la tala cumpliría con las normas europeas de la Directiva 92/43/CCE del Consejo de 21 de mayo de 199254 que debe garantizar la conservación de los habitantes naturales y de la fauna y flora silvestres:
Considerando que en el territorio europeo de los Estados miembros, los hábitats naturales siguen degradándose y que un número creciente de especies silvestres están gravemente amenazadas; que, habida cuenta de que los hábitats y las especies amenazadas forman parte del patrimonio natural de la Comunidad y de que las amenazas que pesan sobre ellos tienen a menudo un carácter trasfronterizo, es necesario tomar medidas a nivel comunitario a fin de conservarlos (...) (Directiva 1992L0043: 2).

Aunque las formas de resistencia de BUND son principalmente demandas, podemos decir que tienen que ver con el

- Método 1 (discursos públicos)

- Método 2 (cartas oposición o de apoyo)

- Método 3 (declaraciones por organizaciones o instituciones)

- y el Método 5 (declaraciones de condena e intención).

\section{Resultados}

En el apartado anterior hemos analizado los motivos, la organización y los métodos de 10 actores involucrados en la resistencia contra la deforestación del Bosque de Hambach. Varias de las actividades demostradas van también contra la extracción del carbón y su utilización como fuente energética.

En total observamos 30 métodos distintos de acción no-violenta propuestos por Sharp (1973) y algunos ejemplos de creación de

\footnotetext{
53 Aunque se explica en la página 10 que el contrato es vigente hasta el año 2040, aquí se trata de que los planes operativos de extracción tienen que ser aprobados de nuevo después de cierto tiempo. 54 Se encuentra la versión en español aquí: https://eur-lex.europa.eu/LexUriServ/LexUriServ.do? uri=CONSLEG:1992L0043:20070101:ES:PDF.
} 
instituciones alternativas, una categoría de acción noviolenta que elaboró Beer (2019). A pesar de que hay muchas personas que actúan de esta manera, varios periodistas y otras personas como el ministro del Interior de NRW describen a los activistas como violentos.

En este apartado queremos discutir sobre la pregunta de investigación: ¿Hasta qué punto fue no-violenta la resistencia? Ya conocimos la autoimagen de los activistas sobre esta pregunta. Ahora nos dedicamos a la atribución externa y compararemos las dos perspectivas. También analizamos qué impacto ha tenido el uso de violencia para el éxito de la resistencia.

Un periodista que deberíamos mencionar aquí es Reiner Burger quien publicó un comentario bajo el título Fanáticos en un país de soñadores 55 en el periódico Frankfurter Allgemeine Zeitung (FAZ) en septiembre de 2018. En este artículo, comentaba que la ocupación en el bosque no era solo un "país de soñadores de una eco-secta inofensiva con admirables ideales climáticos (...). Desde el principio, el asentamiento también albergó a extremistas violentos de izquierda" (Burger, 2018). El argumento popular para criminalizar la resistencia es el supuesto uso de violencia directa contra personas o propiedades. Muchas veces no se distingue entre distintos tipos de violencia y no se define claramente qué es violencia. Un periodista que ha publicado varios artículos que presentan una argumentación parecida a la de Burger, es Marlon Gego quien escribe para los periódicos locales Aachener Zeitung (AZ) y Aachener Nachrichten (AN)56. Según Büttgen (2019), RWE es el cliente publicitario más importante de los periódicos locales AN y AZ. Esto explica por qué muchos artículos incluyen una perspectiva crítica frente a la resistencia.

Cuando se habla de las personas que quieren proteger el Bosque de Hambach en los medios de comunicación, no siempre queda claro a cuáles personas se refieren los periodistas exactamente. Se usa frecuentemente las siguientes descripciones para referirse a los ocupantes del bosque: encapuchados, personas de la izquierda radical, extremistas violentos de la izquierda o eco-terroristas. En dichos artículos, normalmente no se distingue entre las formas de resistencia que hay contra la deforestación del Bosque de Hambach, sino que se generaliza a las personas y a sus estrategias. Como consecuencia, personas que apoyan la resistencia con otros métodos no son mencionadas y no se sabe mucho sobre ellas.

Por la diversidad de las personas que realizan la ocupación, sus motivos y estrategias, resulta difícil aclarar quiénes prefieren actuar sin o con violencia. Según el Ocupante 1, ciertos medios de comunicación, políticos y otros actores intentan separar la resistencia. Büttgen cuenta que ha sido una estrategia de RWE y los políticos poner una cuña entre los llamados ecoterroristas y los ciudadanos desde el principio. "Nos dijeron que nos hacemos cómplices, que también tenemos la culpa. La alianza BUND y nosotros fuimos descritos como cómplices de la escena autónoma en el Parlamento estatal NRW" (Büttgen, 2019).

¿Cómo se posicionan las personas e iniciativas locales frente al uso de violencia y a la criminalización de la resistencia? Lea Heuser se solidariza con acciones de desobediencia civil. Lo que a ella le importa es

55 Título original en alemán: Fanatiker im Phantasieland.

56 En el blog personal de Lea Heuser se puede encontrar una carta de queja abierta formulada por la asociación Premio de Paz de Aquisgrán donde la asociación acusa a Gego por criminalizar la protesta y por no separar sus opiniones personales de los hechos (Heuser, 2018). 
que no se haga uso de violencia directa y física contra personas. Andreas Büttgen de la iniciativa $\mathrm{BfB}$ explica que los miembros decidieron que no se pueden distanciar de todo lo que está pasando en el bosque y que tampoco es posible tener una opinión sobre todos los hechos. Los miembros respaldan acciones de desobediencia civil ejercidos por grupos como Ende Gelände.

Beate Martin y Lea Heuser comentan que la mayoría de las personas del movimiento es pacífica, pero reconocen que algunas sí usan violencia directa. Según ellas, nunca se sabe realmente quiénes son y si realmente son personas que viven en el bosque o si solo están ahí por unos días. A pesar de ello, los actos violentos no han hecho disminuir el nivel de solidaridad con los ocupantes. Al contrario, Beate Martin se dio cuenta de los métodos que la policía o RWE usan para alcanzar sus objetivos y que también se crearía mucha información falsa o se dramatizarían ciertos hechos ${ }^{57}$. Lo mismo cuenta Anna Schönberg de la iniciativa Aktion Unterholz: "El discurso sobre la violencia nos ha acercado aún más porque intercambiamos ideas sobre cómo vamos a reaccionar a esta acusación" (Schönberg, 2019).

Contra la teoría de que la resistencia es violenta, podemos decir que todas las personas, grupos e iniciativas a nivel local y nacional que hemos analizado en este artículo y que forman parte de ella, hacen uso de acciones noviolentas y se oponen a la violencia directa y física, aunque esto no significa que necesariamente se distancian de personas que la usan.
En el transcurso de este análisis se pudo observar que las únicas personas que no se oponen completamente al uso de la violencia directa son las que ocupan el bosque o lo visitan por un tiempo limitado. La mayoría de estas personas se pronuncia en favor de una pluralidad de resistencias para crear vínculos más fuertes y poder actuar juntos contra RWE, el Gobierno y la policía, sus declarados enemigos. El Ocupante 1 explica: "El uso de violencia no debería ser una pregunta ideológica, sino una pregunta táctica después de una consideración madura sobre la pregunta y qué imagen se quiere crear." (Ocupante 1, 2019)

Büttgen cuenta que los primeros ocupantes del bosque tenían un consenso de acción, en la cual decían que estaban ocupando el bosque no-violentamente. Pero desde 2012, la ocupación y las estrategias han cambiado mucho:

"Siempre vinieron más personas y más grupos se formaron. Antes del desalojo en septiembre había 8 o 9 barrios, pueblos de casas-árbol. Eran muy distintos unos de otros, también si nos referimos a la cuestión ¿hasta dónde vamos, sólo hacemos desobediencia civil o también aceptamos que personas dañen o afecten a infraestructuras [de la mina]?". (Büttgen, 2019)

Podemos observar en esta discusión sobre la resistencia en el Bosque de Hambach que se enfoca en la violencia ejercida por las personas que protegen el bosque, mientras que se sabe poco de acciones no-violentas y esfuerzos concretos para crear paz o transformar el conflicto entre las distintas partes del conflicto socio-ambiental. Los

\footnotetext{
57 Un ejemplo es un video que se ha publicado en youtube. Los empleados de RWE sostienen objetos peligrosos como un hacha ante la cámara y dicen que supuestamente se las encontraron en el bosque. Andreas Büttgen dice que estos objetos hacían parte de un depósito de la policía y que estas cosas fueron encontradas en otras ocasiones.
} 
miembros de BfB forman parte de una iniciativa que se fundó en 2016, el así llamado Plan Pacífico58. Ahí conversan representantes de iglesias, partidos políticos, organizaciones ambientalistas, iniciativas ciudadanas $\mathrm{y}$ personas privadas junto con representantes de la empresa RWE sobre la pregunta: ¿cómo se puede lograr un compromiso con respecto al Bosque de Hambach y la extracción de carbón a gran escala en la mina Hambach?

Sin embargo, la disposición de los empleados de RWE para crear un diálogo honesto y buscar soluciones para el conflicto, parece dudosa, por ejemplo, en un informe de prensa publicado el 25 de marzo de 2016, BfB declaró que RWE se enfocaba en métodos que impiden las protestas contra la deforestación. Los miembros de la iniciativa acusan a los empleados de la empresa que evitan mencionar y confrontar la verdadera causa del problema (BfB, 2016).

El hecho de que RWE criminaliza la protesta y que al mismo tiempo se opone a una discusión y la búsqueda de un compromiso, muestra sus intereses económicos claramente: los empresarios no quieren parar la extracción de carbón, ni la quieren limitar. Su objetivo es extraer el carbón por el mayor tiempo posible. Para cumplir esto la resistencia civil es un factor perturbador. Como mencionamos, la extracción de carbón implica múltiples efectos negativos a largo plazo para el medio ambiente, las personas que viven alrededor de las minas y la vida en sí. Con estos datos se podría afirmar que la empresa RWE y el Gobierno alemán ejercen violencia estructural (pues conocen esos efectos negativos). Podemos preguntarnos: ¿Por qué no se habla de esta violencia? Desde este trabajo se plantea que es porque la empresa ha construido un amplio poder político y económico en torno a sus intereses, además apoyados por el Gobierno, se enfocan en el crecimiento económico.

\section{Conclusiones}

El objetivo de este artículo era analizar el movimiento ¡Hambi bleibt! enfocándose en la siguiente pregunta: ¿Hasta qué punto fue noviolenta la lucha contra la deforestación del Bosque de Hambach?

Con respecto a esta pregunta inicial, se puede concluir que 9 de 10 actores que forman parte de la resistencia contra la deforestación enfocan sus actividades en acciones noviolentas. En total se pudo identificar 62 métodos de acción no-violenta que propone Sharp (1973), los más populares son: discursos públicos, manifestaciones, declaraciones, caricaturas/símbolos y banderolas/carteles. Aparte de los actores que nosotros analizamos, hay múltiples grupos solidarios y personas que se oponen a la deforestación 59 . Dado el espacio limitado del trabajo, no se pudo analizar a todos. Así que estos resultados sirven para hacerse una idea sobre la realidad siendo consciente de que se trata de una imagen selectiva.

En varios casos, la información sobre la protesta se limita a la ocupación y no se reconoce a otros actores que están participando. El presente análisis logró ampliar los conocimientos sobre la resistencia $\mathrm{y}$, al mismo tiempo, se entiende como un esfuerzo

\footnotetext{
58 En alemán: Friedensplan.

59 Aquí se encuentra un resumen de los distintos grupos locales que apoyan la resistencia contra la deforestación del Bosque de Hambach ordenados por ciudades: https://Hambacherforst.org/machmit/hambi-supportgruppen/.
} 
para cambiar la perspectiva violentológica hacia una visión más pacífica.

La mayoría de las personas dicen de sí mismas que no hacen uso de violencia directa y física. Esto no significa que se distancian de personas que la usan. La investigación ha mostrado que la auto-percepción de las personas que resisten se distingue profundamente de la atribución externa que reciben, sobre todo la imagen que se da en los medios de comunicación.

En unos artículos, periodistas como Burger (2018) han demandado que la población local debería distanciarse de las personas "violentas" o "criminales" en el bosque. Incluso intentos de dividir la resistencia han fallado. Al contrario, desde 2012 cada vez más personas se han puesto en contra de los planes de la empresa RWE y el Gobierno alemán. Las redes sociales han tenido un impacto clave a la hora de enfrentar situaciones en las cuales se ha intentado criminalizar la protesta. Gracias a Twitter, Instagram y Facebook los activistas pudieron responder inmediatamente a acusaciones de ese tipo. De esta forma, se crean campañas de solidaridad y la resistencia recibió más atención.

Se ha construido un mosaico de distintas luchas y movimientos socio-ambientales: la resistencia contra la deforestación del Bosque de Hambach se puede relacionar con la lucha contra el cambio climático, el movimiento para la justicia ambiental (el Atlas de Justicia Ambiental hace referencia a los ocupantes, la iniciativa BfB, BUND y Greenpeace como actores que buscan una justicia ambiental), la lucha anticapitalista, la búsqueda de nuevas formas de vida basadas en la solidaridad y la comunidad y también con el movimiento feminista.

Aparte de esto, se han experimentado nuevas formas de protesta contra la destrucción del medio ambiente y parece que el miedo de protestar decrece. Consideramos la ocupación del bosque una forma de construcción de instituciones alternativas, una categoría de acción no-violenta que propone Beer (2019).

Pensamos que la manifestación masiva, con aproximadamente 50.000 personas, que tuvo lugar el 6 de octubre de 2018, después de la decisión del Tribunal Administrativo Superior para el Estado de Renania del NorteWestfalia fue un evento clave que demostró el alcance de la resistencia.

Como conclusión, este artículo ha mostrado la importancia que el Bosque de Hambach tiene en el marco de una discusión global sobre el cambio climático y la resistencia civil como instrumento para intentar revertirlo. Se trata de uno de los conflictos socioambientales más potentes en la actualidad y la lucha es un símbolo para la resistencia contra megaproyectos y fuentes de energía norenovables a nivel global. La investigación puede servir para crear un intercambio de experiencias y métodos de lucha no-violentas en distintas regiones del mundo. Nuestras observaciones también pueden servir para científicos que se dedican a la Investigación para la Paz y los conflictos socio-ambientales. 


\section{Referencias bibliográficas}

Aachener Zeitung (14 de marzo de 2017) Das Camp, der Ärger und eine neue Idee. [En línea] http://www.aachener-zeitung.de/lokales/region/das-camp-der-aerger-undeineneueidee-1.1579471 [consultado el 20 de noviembre de 2019]

Adam, Thomas (1998) Die Verteidigung des Vertrauten: Zur Geschichte der Natur- und Umweltschutzbewegung in Deutschland seit Ende des 19. Jahrhunderts, Zeitschrift Für Politik, 45(1), pp. 20-48. [En línea] http://www.jstor.org/stable/24227953 [consultado el 20 de noviembre de 2019]

Alle Dörfer bleiben (2019) Alle Dörfer bleiben. Unsere politischen Forderungen. [En línea] https://www.alle-doerfer-bleiben.de/wp-content/uploads/2019/06/ADB_Forderungen.pdf [consultado el 30 de noviembre de 2019]

Bauchmüller, Michael (15 de septiembre de 2018) Verheizte Heimat, Süddeutsche Zeitung. [En línea] https://www.sueddeutsche.de/politik/hambacher-forst-verheizte-heimat1.4128310 [consultado el 26 de noviembre de 2019]

Beer, Michael (2019) Revisiting the Methods of Nonviolent Action (tentative title), ICNC.

BfB- Buirer für Buir (29 de marzo de 2016) RWE gibt sich gesprächsbereit und verweigert sich doch. [En línea] https://www.buirerfuerbuir.de/index.php/aktuelles/pressemitteilungen/173rwe-gibt-sich-gespraechsbereit-und-verweigert-sich-doch [consultado el 3 de diciembre de 2019]

BMWi- Bundesministerium für Wirtschaft und Energie (2019) Kommission „Wachstum, Strukturwandel und Beschäftigung“. Abschlussbericht. [En línea] https://www.bmwi.de/Redaktion/ DE/Downloads/A/abschlussbericht-kommission-wachstum-strukturwandel-undbeschaeftigung.pdf? blob=publicationFile \&v=4 [consultado el 26 de noviembre de 2019]

BUND NRW (2019a) Braunkohletagebau Hambach. [En línea] https:// www.bundnrw.de/ themen/braunkohle/hintergruende-undpublikationen/braunkohlentagebaue/hambach/40-jahreumweltzerstoerung/ [consultado el 26 de noviembre de 2019]

BUND NRW (2019b) BUND-Klagen gegen die bergrechtlichen Zulassungen. [En línea] https://www.bund-nrw.de/themen/braunkohle/hintergruende-undpublikationen/ braunkohlentagebaue/hambach/bund-klagen-gegen-hambach/ [consultado el 30 de noviembre de 2019]

Burger, Reiner (25 de septiembre de 2018) Kommentar zum Hambacher Forst: Fanatiker im Phantasieland, Frankfurter Allgemeine Zeitung. [En línea] https:/www.faz.net/aktuell/politik/ inland/ueber-gewalttaetige-linksextremisten-imhambacher-forst-kommentar-15804583.html [consultado el 30 de noviembre de 2019]

Carter, April (2012) People power and political change. Key issues and concepts, London y New York, Routledge.

Casey, Joan A.; Gemill, Alison.; Karasek, Deborah., et al. (2018) Increase in fertility following coal and oil power plant retirements in California, Environmental Health: A Global Access Science Source, 17(44). DOI: 10.1186/s12940-018-0388-8 [

Chatterton, Paul y Pickerill, Jenny (2010) Everyday activism and transitions towards postcapitalist worlds. Royal Geographical Society (con el Transactions of the Institute of British Geographers), 35(4), pp. 475-490. [En línea] http://www.jennypickerill.info/wp-content/uploads/ Chatterton-and-Pickerill-2010-Transactions-Published.pdf [consultado el 30 de noviembre de 2019] 
Chenoweth, Erica y Stephan, Maria J. (2011) Why civil resistance works: The strategic logic of nonviolent conflict, New York, Columbia University Press.

Directiva 1992L0043 (21 de mayo de 1992) DIRECTIVA 92/43/CEE DEL CONSEJO de 21 de mayo de 1992 relativa a la conservación de los hábitats naturales y de la fauna y flora silvestres. [En línea] https://eurlex.europa.eu/LexUriServ/LexUriServ.do? uri=CONSLEG:1992L0043:20070101:ES:PDF [consultado el 30 de noviembre de 2019]

Evans, Simon (29 de enero de 2019) Analysis: How far would Germany's 2038 coal phaseout breach Paris climate goals? [En línea] https://www.carbonbrief.org/analysis-howfarwouldgermanys-2038-coal-phaseout-breach-paris-climategoals? $\underline{\text { utm } \text { source }=\text { TwitterVid\&utm campaign }=\text { CoalPhaseOut0119 }}$ [consultado el 26 de noviembre de 2019]

FfF - Fridays for Future (2019) Strike List Countries. [En línea] https://fridaysforfuture.org/ events/list [consultado el 26 de noviembre de 2019]

Fraunhofer (2018) Stromerzeugung in Deutschland im Jahr 2017. [En línea] https:// www.ise.fraunhofer.de/content/dam/ise/de/documents/publications/studies/datenzuerneuerbarenenergien/Stromerzeugung_2017.pdf [consultado el 26 de noviembre de 2019]

Halvorsen, Sam (2015) Taking Space: Moments of Rupture and Everyday Life in Occupy London, A Radical Journal of Geograhy (Antipode), 47(2), pp. 401-417. [En línea] https:// onlinelibrary.wiley.com/doi/abs/10.1111/anti.12116 [consultado el 30 de noviembre de 2019]

Hambacherforst (2015) Mit Baumhäusern gegen Bagger: Geschichten vom Widerstand im rheinischen Braunkohlerevier.

Hambacherforst (2019) [En línea] https://hambacherforst.org/ [consultado el 30 de noviembre de 2019]

Heuser, Lea (2018) Offener Beschwerdebrief des Aachener Friedenspreis e.V. an die Chefredaktion von Aachener Nachrichten und Aachener Zeitung. [En línea] https:// kommunikatz.wordpress.com/2018/05/12/offener-beschwerdebrief-des-aachenerfriedenspreis-evan-die-chefredaktion-von-aachener-nachrichten-und-aachener-zeitung/ [consultado el 30 de noviembre de 2019]

Jänicke, Martin; Kunig, Phili y Stitzl, Michael (1999) Lern- und Arbeitsbuch Umweltpolitik. Politik, Recht und Management des Umweltschutzes in Staat und Unternehmen, Bonn, Bundeszentrale für politische Bildung.

Kaufer, Ricardo y Lein, Paula (2018) Widerstand im Hambacher Forst: Analyse einer anarchistischen Waldbesetzung. [En línea] https://www.researchgate.net/publication/ 328932749 Widerstand_im_Hambacher_Forst_Ana lyse einer_anarchistischen_Waldbesetzung [consultado el 30 de noviembre de 2019]

Kohle Ersetzen (20 de septiembre de 2018) PM: Klimaschützer appellieren vor Gericht an das Gewissen. [En línea] http://www.kohle-ersetzen.de/pm-klimaschuetzer-appellierenvor-gerichtandas-gewissen/ [consultado el 27 de noviembre de 2019]

Kölner Stadtanzeiger (25 de abril de 2016) Hambacher Forst. Braunkohlegegner setzen Starkstromleitung in Brand. [En línea] http://www.ksta.de/region/rhein-erft/kerpen/hambacherforst-braunkohlegegner-setzen-starkstromleitung-in-brand-23952182 [consultado el 30 de noviembre de 2019] 
La Vanguardia (8 de octubre de 2018) El emblemático bosque Hambach gana una batalla judicial a la minería de carbón. [En línea] https://www.lavanguardia.com/natural/ 20181008/452233588178/el-emblematico-bosquehambach-gana-una-batalla-judicial-a-lamineriade-carbon.html [consultado el 26 de noviembre de 2019]

López-Martínez, Mario (2006) Politica sin violencia. La noviolencia como humanización de la política, Bogotá, Universidad Minuto de Dios, Conferencia Norteamericana de Obispos Católicos y Movimiento Ciudadano por la Noviolencia en Colombia.

López-Martínez, Mario (2015) Nonviolence in social sciences: towards a consensual definition, Revista de paz y conflictos, 8(1), pp. 63-81.

López-Martínez, Mario (2016) La resistencia civil examinada: de Thoreau a Chenoweth. Polis, Revista Latinoamericana, 15(43), pp. 41-65.

Marquardt, Ralf-M. (2015) Strukturwandel im rheinischen Revier: Risiken und Chancen. [En línea] https://www.nachhaltiglinks.de/images/DateienJ2/3 Energie/2 PDF/ F a c h g e s p r \% C 3 $\% \mathrm{~A} 4 \mathrm{ch}=\mathrm{Strukturwande} 1 / \mathrm{Rh}$ e in i s c e s $\mathrm{R}$ e vie r Pr\%C3\%A4sentation_Prof._Marquardt.pdf [consultado el 30 de noviembre de 2019]

Müller, Benedikt (30 de noviembre de 2017) Peruanischer Bauer bringt RWE vor Gericht, Süddeutsche Zeitung. [En línea] https://www.sueddeutsche.de/wirtschaft/klimawandelperuanischerbauer-bringt-rwe-vor-gericht-1.3772256 [consultado el 26 de noviembre de 2019]

Nepstad, Sharon Erickson (2015) Nonviolent Struggle - Theories, Struggles, \& Dynamics, New York, Oxford University Press.

Olschimke, Michael (2019) Blog personal. [En línea] http://www.olschimke.eu/activities/ projects/198-methods-of-nonviolent-action/ [consultado el 30 de noviembre de 2019]

Parth, Christian (9 de abril de 2019) Gutachten von RWE bestellt: Regierung zahlte Gutachten vor Einsatz im Hambacher Forst, Kölner Stadtanzeiger. [En línea] https://www.ksta.de/region/ raeumung-von-rwe-bestellt--regierung-zahlte-gutachten-voreinsatz-im-hambacher-forst-32352298 [consultado el 30 de noviembre de 2019]

Pfeifer, Thomas; Schneider, Tim y Stadtmann, Mats (2017) Aktivismus im Hambacher Forst Alltag als politisches Mittel, Geographisches Institut der Rheinischen FriedrichWilhelmsUniversität Bonn, SoSe 2017. [En línea] https://www.researchgate.net/publication/

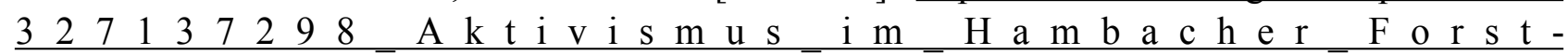
Alltag_als_politisches Mittel_Entstanden_im_Rahmen_des_Forschungsprojektes_Globale politisc he Okologien_der_Kohle_im Masterstudiengang_Geographie [consultado el 30 de noviembre de 2019]

Reinhardt, Tanja y Laaks, Jörg (2018) Bäume oder Braunkohle? Der Kampf um den Hambacher Forst, Westdeutscher Rundfunk (WDR). [En línea] https://www.youtube.com/watch?

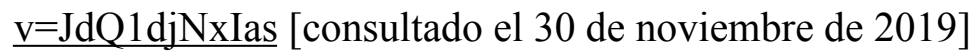

Scheidel, Arnim (2015) Hambach forest occupation against brown coal mining, Germany, Environmental Justice Atlas. [En línea] https://ejatlas.org/conflict/occupation-of-the-hambacherforst-against-brown-coal-mining-germany [consultado el 27 de noviembre de 2019]

Scott, James C. (1989) Everyday Forms of Resistance. Copenhagen Journal of Asian Studies, 4, pp. 33-62. [En línea] https://rauli.cbs.dk/index.php/cjas/article/download/1765/1785 [consultado el 30 de noviembre de 2019] 
Sharp, Gene (1973) The Politics of Nonviolent Action. A detailed (3 volume) analysis of specific methods of nonviolence, Boston, Porter Sargent.

UBA- Umweltbundesamt (2017) Daten und Fakten zu Braun- und Steinkohlen. [En línea] https://www.umweltbundesamt.de/sites/default/files/medien/1410/publikationen/171207_uba hg_braunsteinkohle bf.pdf [consultado el 26 de noviembre de 2019]

UKSCN- UK Student Climate Network (2019) Página web de la organización. [En línea] https://ukscn.org/ys4c [consultado el 27 de noviembre de 2019]

Vinthagen, Stella (2015) A theory of nonviolent action. How civil resistance works, Londres, Zed Books.

Wernicke, Christian (13 de septiembre de 2018) Polizei räumt Hambacher Forst, Süddeutsche Zeitung. [En línea] https://www.sueddeutsche.de/politik/besetzter-waldimrheinischenbraunkohlerevier-polizei-raeumt-hambacher-forst-1.4127664 [consultado el 30 de noviembre de 2019]

\section{Entrevistas realizadas en 2019}

Entrevistado 3

Büttgen, A.

Heuser, L.

Martin, B.

Ocupante 1

Ocupante 2

Schönberg, A.

Töller, E.

Zobel, M.

PROCESO EDITORIAL $\bullet$ EDITORIAL PROCESS INFO

Recibido: 11/12/2019 Aceptado: 02/02/2020

\section{CÓMO CITAR ESTE ARTÍCULO • HOW TO CITE THIS PAPER:}

Gerstenberg, Feline (2019). Resistencia civil contra megaproyectos. Análisis del movimiento ¡Hambi bleibt! en Alemania. Revista de Paz y Conflictos, Vol.12 (2), 81-109.

\section{SOBRE LOS AUTORES • ABOUT THE AUTHORS}

Feline Gerstenberg obtuvo un Grado en Ciencias Sociales (Universidad de Heinrich-Heine Düsseldorf) en 2017; realizó una Estadía de Investigación en la Universidad Católica de Colombia (febrero a julio de 2017); obtuvo un Master de Cultura de Paz, DDHH, Conflictos y Educación (Universidad de Granada, IPAZ) en 2019. 